\title{
Achieving Superior Tropical Cyclone Intensity Forecasts by Improving the Assimilation of High-Resolution Satellite Data into Mesoscale Prediction Models
}

\author{
PI: Christopher Velden \\ University of Wisconsin - SSEC \\ 1225 W. Dayton St., Rm 229 \\ Madison, WI 53706 \\ Phone: (608) 262-9168 Fax: (608) 262-5974 \\ Email: chrisv@ssec.wisc.edu \\ CO-PI: Sharanya J. Majumdar \\ RSMAS/MPO, University of Miami, 4600 Rickenbacker Causeway, Miami, FL 33149 \\ Phone: (305) 4214779 Fax: (305) 4214696 \\ Email: smajumdar@rsmas.miami.edu \\ CO-PI: Jun Li \\ University of Wisconsin - SSEC, 1225 W. Dayton St., Rm 201, Madison, WI 53706 \\ Phone: (608) 262-3755 Fax: (608) 262-5974Ｅmail: jun.li@ssec.wisc.edu \\ CO-PI: Hui Liu \\ Institute for Mathematics Applied to Geosciences, NCAR, Boulder, CO 80503 \\ Phone: (303) 4971304 Email: hliu@ucar.edu \\ CO-PI: James D. Doyle (separate funding) \\ Naval Research Laboratory, 7 Grace Hopper Avenue, Monterey, CA 93943-5502 \\ Phone: (831) 656-4716 Fax: (831) 656-4769 \\ Email: james.doyle@nrlmry.navy.mil \\ CO-PI: Jeffrey Hawkins (separate funding) \\ Naval Research Laboratory, 7 Grace Hopper Avenue, Monterey, CA 93943-5502 \\ Phone: (831)-656-4833 Fax: (831)-656-5025 \\ Email: Jeffrey.hawkins@nrlmry.navy.mil
}

Award Number: N00014-10-1-0123

\section{LONG-TERM GOALS}

Forecasts of TC intensity change are often lacking in skill due in part to the paucity of conventional observations over the oceans that are assimilated into the operational models. The inability to accurately map the three-dimensional atmosphere and the underlying upper ocean has also constrained our understanding of how intensity fluctuations are governed by internal and environmental processes. Remotely-sensed 


\section{Report Documentation Page}

Form Approved

OMB No. 0704-0188

Public reporting burden for the collection of information is estimated to average 1 hour per response, including the time for reviewing instructions, searching existing data sources, gathering and maintaining the data needed, and completing and reviewing the collection of information. Send comments regarding this burden estimate or any other aspect of this collection of information,

including suggestions for reducing this burden, to Washington Headquarters Services, Directorate for Information Operations and Reports, 1215 Jefferson Davis Highway, Suite 1204, Arlington

VA 22202-4302. Respondents should be aware that notwithstanding any other provision of law, no person shall be subject to a penalty for failing to comply with a collection of information if it

does not display a currently valid OMB control number.

1. REPORT DATE

SEP 2012

2. REPORT TYPE

3. DATES COVERED

00-00-2012 to 00-00-2012

4. TITLE AND SUBTITLE

Achieving Superior Tropical Cyclone Intensity Forecasts by Improving the Assimilation of High-Resolution Satellite Data into Mesoscale Prediction Models

5a. CONTRACT NUMBER

5b. GRANT NUMBER

5c. PROGRAM ELEMENT NUMBER

6. $\operatorname{AUTHOR}(\mathrm{S})$

5d. PROJECT NUMBER

5e. TASK NUMBER

5f. WORK UNIT NUMBER

7. PERFORMING ORGANIZATION NAME(S) AND ADDRESS(ES)

University of Wisconsin -SSEC,1225 W. Dayton St., Rm

229,Madison,WI,53706

9. SPONSORING/MONITORING AGENCY NAME(S) AND ADDRESS(ES)

10. SPONSOR/MONITOR'S ACRONYM(S)

11. SPONSOR/MONITOR'S REPORT NUMBER(S)

12. DISTRIBUTION/AVAILABILITY STATEMENT

Approved for public release; distribution unlimited

13. SUPPLEMENTARY NOTES

14. ABSTRACT

15. SUBJECT TERMS

16. SECURITY CLASSIFICATION OF:

a. REPORT

unclassified b. ABSTRACT unclassified c. THIS PAGE unclassified
17. LIMITATION OF ABSTRACT

Same as

Report (SAR)
18. NUMBER OF PAGES

18 19a. NAME OF

RESPONSIBLE PERSON
8. PERFORMING ORGANIZATION REPORT NUMBER 
observations from multiple satellite sources have become more routinely available as part of the atmospheric/oceanic observing system. As an important input to global numerical data assimilation and forecast systems, these data are providing crucial large-scale environmental information for better predicting such parameters as TC steering flow fields. However, in regard to TC intensity change, it is clear that a dedicated research effort is needed to optimize the satellite data processing strategies, assimilation, and applications within a higher resolution modeling framework. Contemporary strategies developed for assimilating satellite data into global NWP systems appear to be inadequate for retaining information on the scales of processes pertinent to TC analysis and intensity change. Our study attempts to focus on and evaluate the impact of integrated, full resolution, multi-variate satellite data on TC intensity forecasts using advanced data assimilation methods and coupled ocean-atmosphere mesoscale forecast models. The development of successful strategies to optimally assimilate satellite-derived data should ultimately lead to improved numerical forecasts of TC intensity.

\section{OBJECTIVES}

The ultimate goal of this project is the development and refinement of a capability to supplement the contemporary atmospheric observation network with optimal configurations and assimilation of advanced satellite-derived observations, to improve high-resolution operational analyses and intensity forecasts of TCs.

The primary objectives are to prepare a comprehensive database of full-resolution observations from multiple satellite platforms for selected TC case studies, for provision to the Navy, NOAA and NCAR collaborators in this study and other NOPP-funded studies. Then quantify how best to utilize the multiple satellite datasets in applications to TC structure/intensity prediction, using advanced data assimilation and high-resolution forecast models. Finally, provide a pathway towards advanced satellite data assimilation in the emerging operational TC forecast models (i.e. HWRF, COAMPS-TC).

\section{APPROACH}

Our approach is to first investigate and optimize the assimilation of the satellite data in the WRF ensemble-based assimilation system. The COAMPS-TC system is now also being employed in our later efforts. In the evaluation phase, the investigators are analyzing the parallel model analyses and forecasts that assimilate and do not assimilate the satellite data. In this manner, the utility of the various satellite data in improving TC intensity analyses/predictions is being assessed. The main science focus is on investigating and understanding how the assimilation of the satellite data modifies the model analyses and forecasts of TC structure. Moreover, the improvement in model representation of important synoptic features such as adjacent trough interactions, outflow channels, and available environmental moisture is expected to benefit the numerical forecasts of TC intensities. The effects of assimilating data from multiple satellite platforms are being investigated for each individual platform, and for combinations of platforms. Typhoon Sinlaku and Hurricane Ike, both from 2008, have been targeted as primary case studies. 


\section{WORK COMPLETED AND RESULTS}

In Year 3, we addressed the following tasks (responsible team members in parentheses):

1) Continued satellite data assimilation trials using EnKF/WRF. (NCAR)

2) Analysis and evaluation of WRF trials. (UMiami, CIMSS, RAMMB, NRL-H)

3) Began COAMPS-TC experiments. (NRL-D)

4) Began investigating an optimal bogus TC insertion that uses the satellite information. (CIMSS, UMiami)

5) Presented preliminary results. (All)

\section{CIMSS-PI Velden}

As described in the previous annual report, a novel bogus ensemble data assimilation approach was developed in order to assess the impact of the enhanced AMV observations at high model resolution (i.e. $<4 \mathrm{~km}$ spacing). It involves sampling an ensemble of bogus vortices from selected parameters given in the tcvitals file, and then assimilating the AMV observations using an ensemble Kalman filter. The resulting ensemble mean analysis is then used to initialize a deterministic forecast using the UW-NMS model. While sacrificing the flow-dependent error covariances implicit in analysis cycling, this method has the advantage of allowing much higher model resolution for a fraction of the computational expense. Initial tests for Ike were encouraging, demonstrating an improvement in the intensity forecast relative to a control case in which no special AMV observations were assimilated. However, additional testing over the full life cycle of Ike (46 separate analyses) revealed that the bogus vortex insertion resulted in an inadequate representation of the environmental flow in the neighborhood of the TC, resulting in an unacceptably large number of AMV observations being rejected by the quality control algorithm. To address this shortcoming, a more sophisticated bogus algorithm is employed and tested in conjunction with a short-window (6-hour) assimilation strategy. Such an approach retains the advantage of high model resolution but also allows for a better representation of the environment in the vicinity of the TC as well as the development of some degree of flow-dependence in the error covariances. This should allow a greater impact of the AMV observations on the resulting high-resolution analysis.

In this reporting period, the scheme has been adapted to work within the Developmental Testbed Center's (DTC) Gridpoint Statistical Interpolation (GSI V3.0) framework, specifically for implementation as a hybrid data assimilation system using the Weather Research and Forecast (WRF) model. Among many other advantages, this permits greater compatibility with other efforts ongoing within our group and the research community at large. Using this scheme, the impacts of enhanced atmospheric motion vectors (AMVs) on analyses and forecasts of Hurricane Ike (2008) were investigated over 10 separate data assimilation windows, each initialized at $00 \mathrm{Z}$, covering the period from 03 SEP 2008 - 12 SEP 2008. The CTL experiment consisted of a 6-hr spin-up period, after which assimilation of conventional observations (NCEP PREPBUFR) took place at 6-hr intervals. The impact experiment (EXP3HR) augmented the CTL with the assimilation of enhanced AMVs from CIMSS at 3-hrly intervals. Results indicate that incorporation of the high-resolution AMVs aid in systematically reducing errors in TC 
position, minimum central pressure and maximum sustained wind speed (see Table 1). It is also noted that the surface wind fields produced in EXP3HR compare more favorably with the independent surface-wind analyses produced by CIRA (e.g. Figure 1). In particular, the surface wind analyses obtained in EXP3HR are not as broad as in CTL, suggesting that, apart from improving TC position and intensity, the high-resolution AMV data may contribute to improved representation of TC size as well.

\begin{tabular}{|l|l|l|}
\hline & $\begin{array}{l}\text { CTL } \\
\text { RMSE (BIAS) }\end{array}$ & $\begin{array}{l}\text { EXP3HR } \\
\text { RMSE(BIAS) }\end{array}$ \\
\hline Position $(\mathrm{nm})$ & 25.9 & 22.0 \\
\hline Min SLP $(\mathrm{hPa})$ & $12.8(+11.8)$ & $10.6(+9.7)$ \\
\hline Max Wind $(\mathrm{kt})$ & $21.0(-20.7)$ & $19.5(-19.3)$ \\
\hline
\end{tabular}

Table 1. RMS errors and biases for the CTL and EXP3HR experiments (values represent the mean of all 6-hr forecasts conducted within each data assimilation window, i.e. 10 DA windows x 4 6-hr forecasts -> sample size $=40$ ).
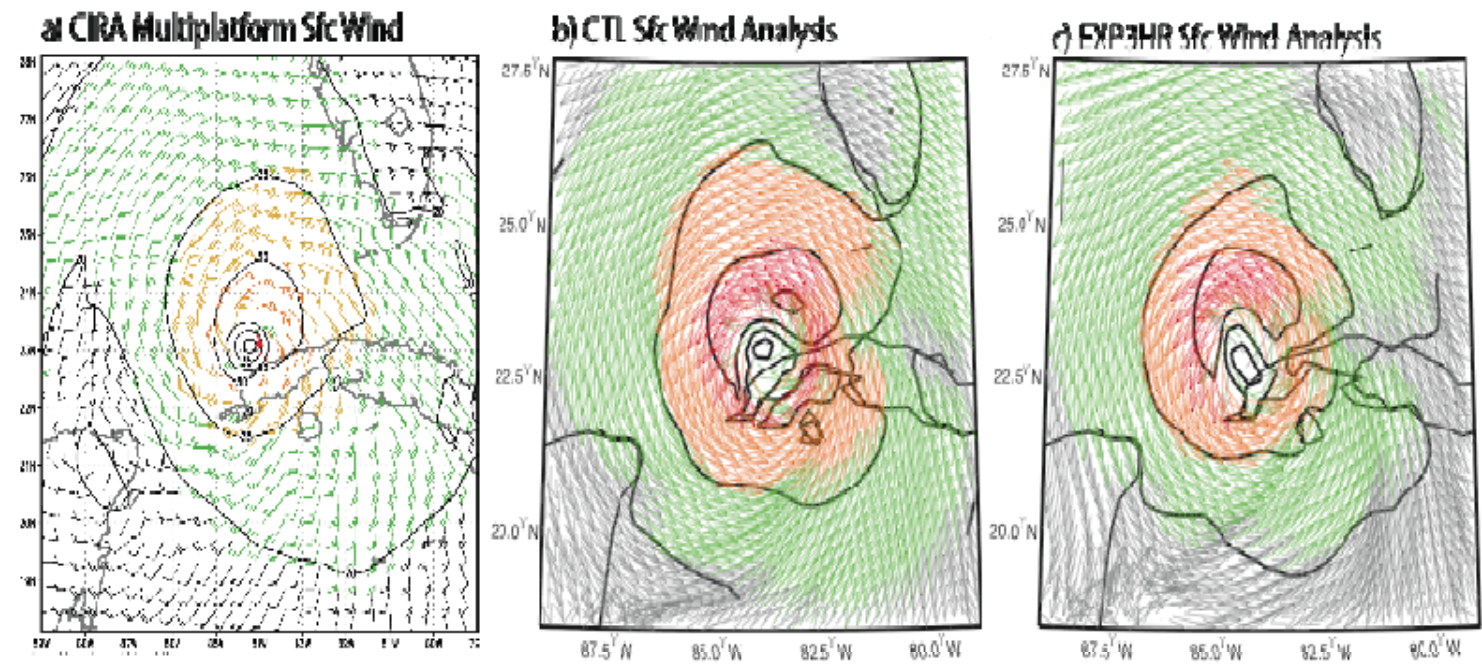

Figure 1. Surface wind valid at 00Z 10 SEP 2008, from: a) CIRA multiplatform analysis, b) CTL and c) EXP3HR. 


\section{CIMSS-PI Li}

\subsection{Experiments on microwave sounder and advanced IR sounder data for hurricane forecasts}

In order to understand the impact of assimilating advanced IR sounder and microwave sounder data on tropical cyclone forecasts, conventional data (GTS), AIRS radiances and AMSU radiances are used in numerical forecast experiments for Hurricane Irene (2011, Fig. 2). The following experiments are conducted with WRF/GSI:

GTS (conventional data)

GTS + AIRS radiances

GTS + AIRS radiances + AQUA(1 AMSU from Aqua)

GTS + AIRS radiances + 4 AMUSA (4 AMSU from NOAA 15, NOAA18, Metop-A and Aqua)

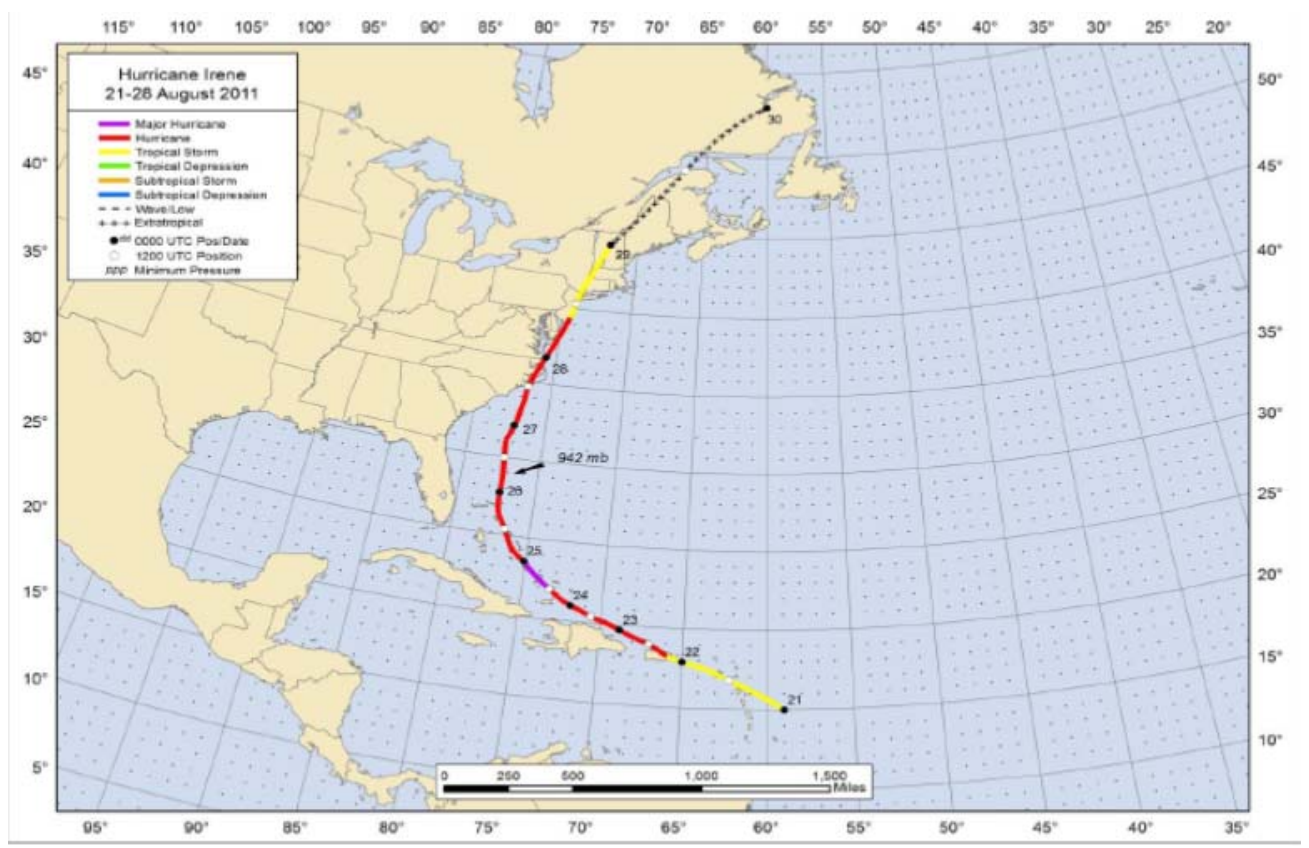

Figure 2. Hurricane Irene (2011) track and intensity evolution.

In all of the assimilation experiments, data are assimilated every 6 hours from 06 UTC August 22 to 00 UTC August 24, 2011 followed by 48-hour forecasts after each assimilation. The spatial resolution of WRF is $12 \mathrm{~km}$ in these experiments. Considering the temporal variability of atmospheric temperature and moisture in regional NWP, the assimilation window is 3 hours (plus/minus 1.5 hours) which is smaller than that in global data assimilation (plus/minus 3 hours). Figure 3 shows the track and intensity (central sea level pressure) root mean square error (RMSE) for the forecasts of 00 hour, 
06 hour, ...., and 48 hours. The 00 hour forecast is from the analysis after assimilation. AIRS and AMSU radiances are assimilated in these experiments, and the channels used are the same as those used operationally in the NCEP global NWP models (e.g., GFS). It can be seen than when GTS, AIRS and all available AMSU (NOAA15, NOAA18, Aqua and Metop $-\mathrm{A}$ ) are used together, the hurricane track and intensity forecasts have the best accuracy (smallest RMSEs), indicating that both advanced IR and microwave sounder data are needed for improving the tropical cyclone forecasts.
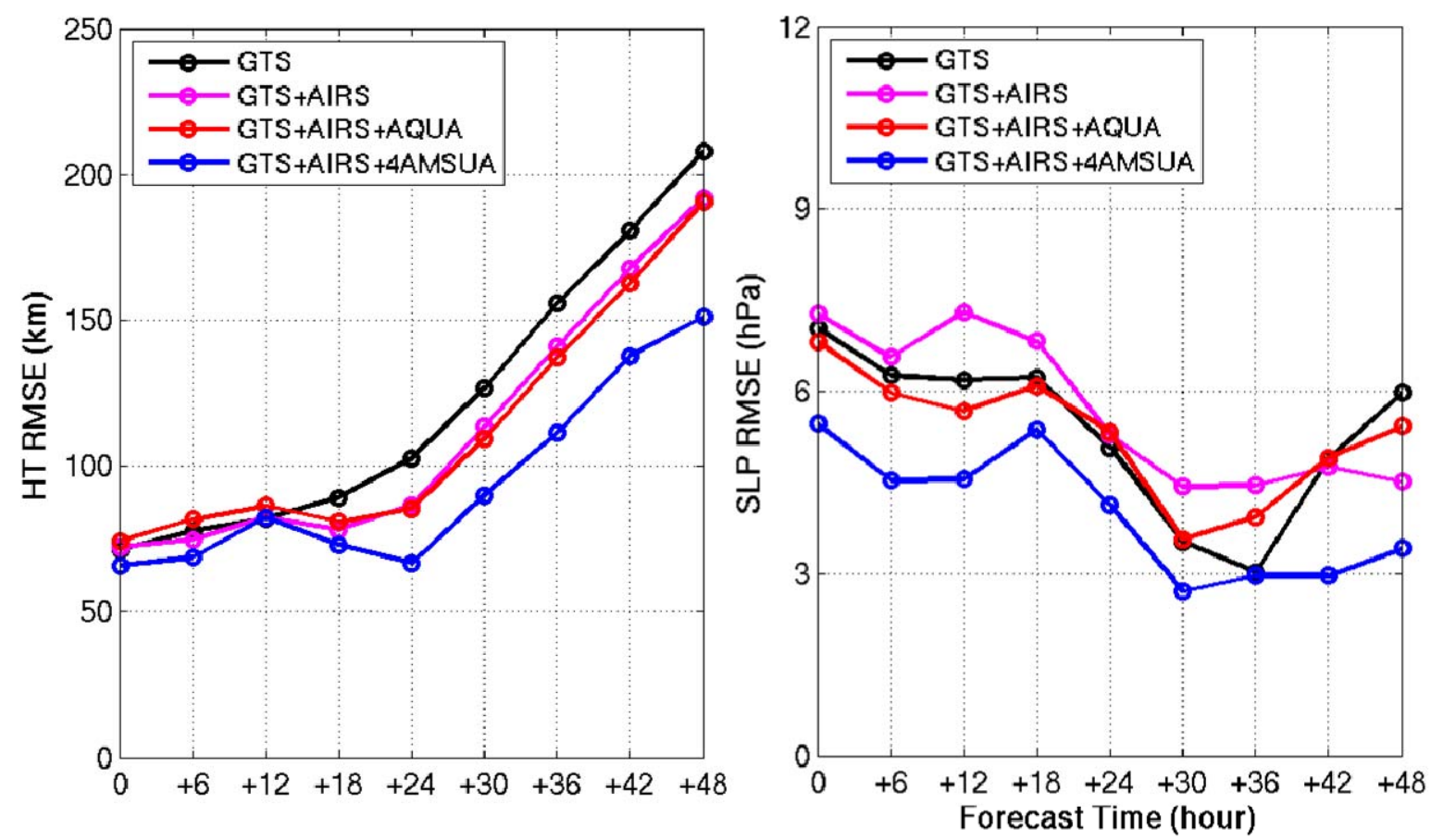

Figure 3. Track (left) and intensity (central sea level pressure, right) root mean square error (RMSE) for Hurricane Irene forecasts (00-48 hours).

\subsection{Experiments on assimilating IR radiances versus soundings for tropical cyclone forecasts}

In order to understand the pros/cons between assimilating radiances vs. soundings on TC analyses and forecasts, the CIMSS sounding team have conducted selected experiments to test the impacts. Since AIRS single field-of-view (SFOV) soundings are available, we are able to conduct the experiments with WRF/GSI. The data are assimilated every 6 hours from 06 UTC 22 August 2011 to 00 UTC 23 August 2012 followed by 48 hour forecasts. Three experiments are conducted:

(1) GTS (conventional data);

(2) GTS + AIRS radiances;

(3) GTS + AIRS SFOV soundings.

In order to evaluate just the impact of AIRS radiances vs. soundings, the AMSU data are not used in the above experiments. Figure 4 shows the track and intensity (SLP) RMSE for all the forecasts of 00 hour, 06 hour, ...., and 48 hours. It can be seen that for track 
forecasts, both AIRS radiances and soundings generally improve upon the GTS-only for forecasts, but some time periods yield mixed results. In addition, assimilating soundings provides better track results than assimilating radiances, except at 12 and 18 hours. For SLP, both radiances and soundings provide better SLP forecasts than GTS except for 06and 12-hour forecasts. Assimilating soundings vs. radiances provides mixed results. Additional experiments are onging, for example, when AMSU data are also included, what is the impact between assimilating radiances and assimilating soundings? And inclusion of bias adjustments (both for radiances and soundings) will also be investigated.
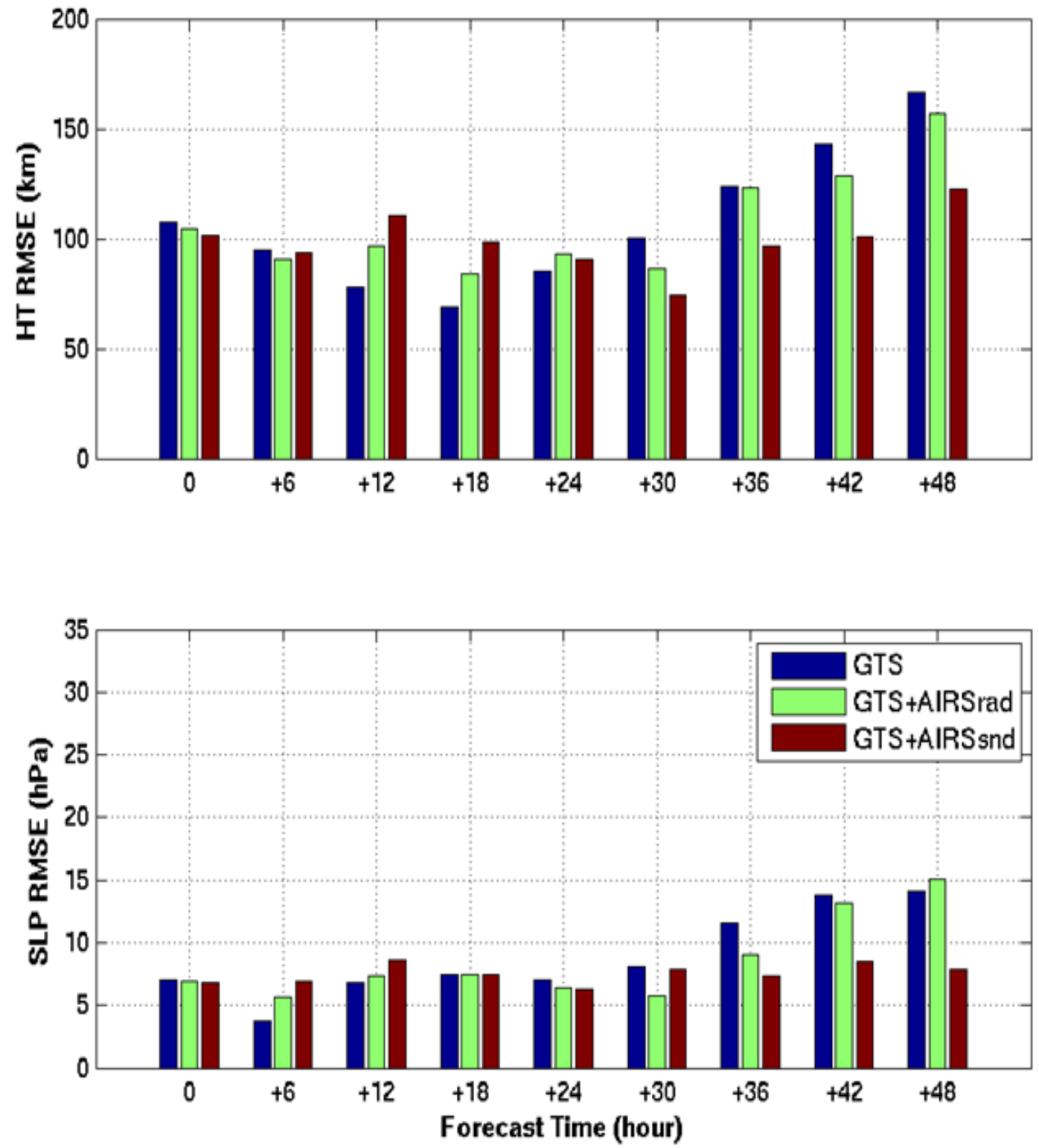

Figure 4. Hurricane Irene (2011) track (upper panel) and intensity (lower panel) RMSE for model forecasts at $00-48$ hours. In this experiment, AMSU radiances are not used. 


\section{NRL/MRY-PI Doyle}

As part of the COAMPS-TC effort, work has continued toward the development, testing, and validation of the ensemble Kalman filter (EnKF) data assimilation system implemented with the Data Assimilation Research Testbed (DART). Real-time validation and testing of the system was performed during the 2012 Atlantic hurricane season. Under the NOPP project, AMSU-A brightness temperature and Global Positioning Satellite Radio Occultation (GPS-RO) bending angle observations were implemented into the system and assimilated into COAMPS-TC during the real-time experiments. Initial verification of innovation statistics for each observation type was performed and future research will focus on the impact of the data.

Brightness temperature data from the AMSU-A instrument was directly assimilated in COAMPS-TC using the Community Radiative Transfer Model (CRTM) as the forward operator. While global model data assimilation systems have successfully assimilated radiance observations for over a decade, this success has not been duplicated in limited area mesoscale models. This is due in part to the inability of mesoscale models to effectively calculate bias-corrections over their limited domain and finite dataassimilation cycling intervals. Furthermore, mesoscale models have been unable to assimilate radiance channels which peak in the upper troposphere and lower stratosphere due to limitations imposed by the relatively low model top. To address the first issue, bias coefficients derived from the NAVDAS-AR 4D-VAR system were used to correct the observational bias. Figure 5 shows the mean innovation statistics as a function of AMSU-A channel number for the set of the COAMPS-TC prior forecasts of Tropical Storm Isaac (2012). The innovations have been normalized by the ensemble variance. With the exception of channel 7 from NOAA 16 and channel 8 from NOAA 19, the innovation statistics show that the global model coefficients are effective in reducing the observation bias. Using global model bias corrections may circumnavigate the need to cycle the mesoscale model for an extending period of time to compute bias coefficients.

In addition to AMSU-A data, the system also assimilated GPS-RO bending angle observations using the community supported Radio Occultation Preprocessing Package (ROPP) as the forward operator. Compared with refractivity, which is commonly assimilated in the DART system, bending angle is a more direct observation and has greater potential to sample deeper into the troposphere. Data from the COSMIC constellation as well data from the NASA GRACE and EUMETSAT GRAS instruments were assimilated. Figure 6 shows the normalized innovation statistics for all bending angle observations during the life time of Leslie (2012) and Nadine (2012) through 12 UTC 15 September. The bending angle observation counts generally peak in the stratosphere; however, the system is assimilating data as low as $3 \mathrm{~km}$. Since bending angle observations are un-biased, the innovation bias is a reflection of model bias. Over the depth of the domain the innovations are relatively un-biased, however a few features are apparent in the profile. The first is a relatively sharp negative bias at about $14 \mathrm{~km}$ which corresponds to the level of the tropical tropopause. The second is a broader negative bias in the mid-stratosphere between 30 and $35 \mathrm{~km}$. The source of this bias is unknown and will be the target of future research. 

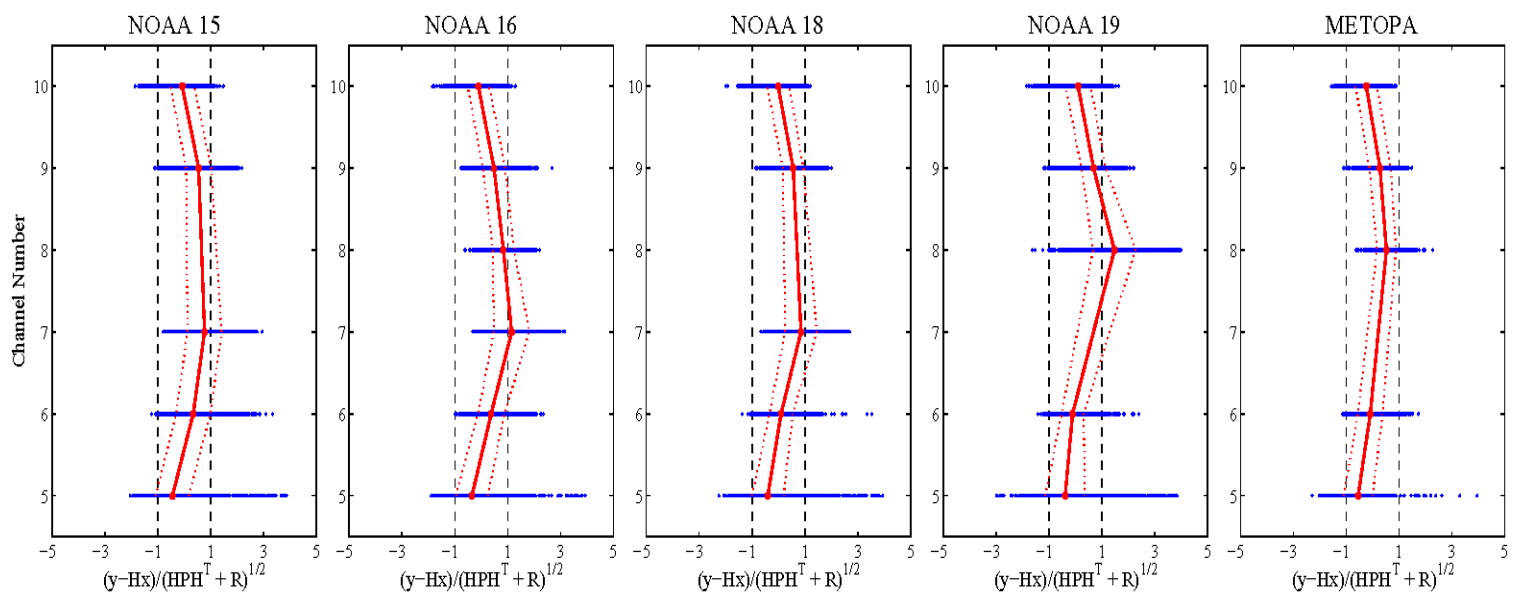

Figure 5: The normalized mean innovation as a function of channel number (red solid) for the life-cycle of tropical storm Isaac for AMSU-A brightness temperature observations. Each panel represents the statistics from a different satellite platform. The innovations are normalized by the ensemble variance. The red dotted curves show the plus/minus one standard deviation from the mean innovations and the blue markers indicate the range of innovation values that were assimilated into the system.

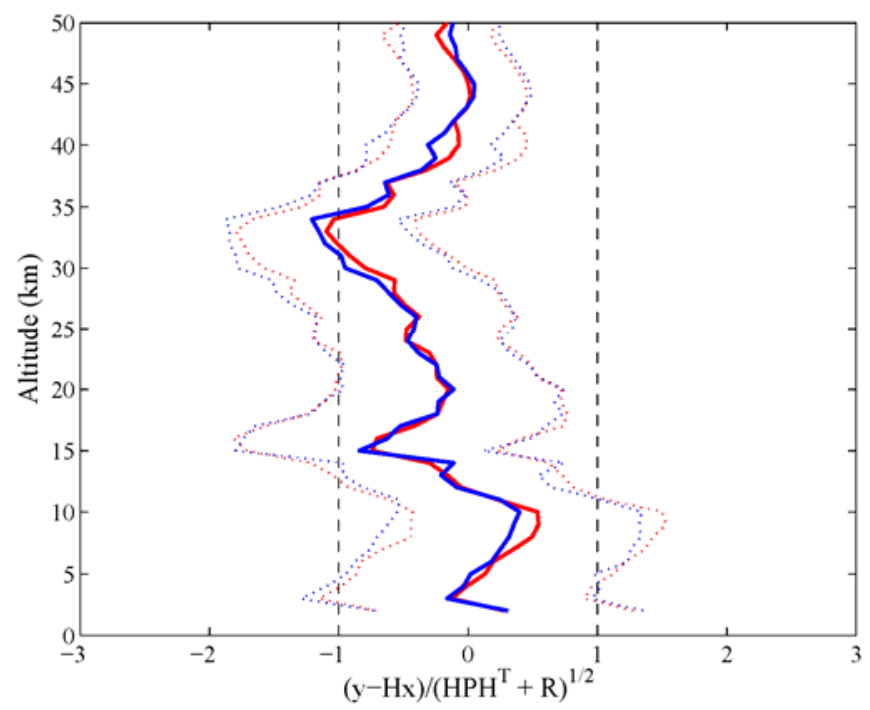

Figure 6: The normalized mean innovations of GPS-RO bending angle observations as a function of height for tropical storm Leslie (red solid) and Nadine (blue solid). The innovations have been normalized by the ensemble variance and plus/minus one standard deviation are depicted by the dotted curves. 


\section{UCAR-PI Liu}

\section{WRF/DART system developments}

Due to the increased availability of computational power, and the need to improve the error covariance structure in the EnKF data assimilation, much effort was focused on increasing the ensemble size from 32 to 84, and upgrading the microphysics in WRF from WSM 5 class to WSM 6 class. All the parallel assimilation-forecast cycles reported in Years 1 and 2 were rerun with this new, improved configuration.

The main finding was that the analyses using CIMSS AMVs and all observation types together were fairly similar for the old 32- and new 84-member ensembles. However, the differences between the old and new analyses were substantial for the assimilation of AIRS moisture soundings and TPW, suggesting that the larger ensemble size is necessary for the assimilation of water vapor observations.

Several additional tests were conducted. First, methods to reduce the sampling error were found to produce little change to the analysis fields. Second, various localization cut off distances were investigated. It was found that the current configuration (half-width cutoff $=650 \mathrm{~km}$ ) remained the optimal one.

\section{Overview of data assimilation experiments}

The following series of experiments was performed to evaluate the impact of assimilating rapid-scan winds, AIRS temperature and moisture soundings, and AMSR TPW on ensemble analyses and predictions of tropical storm / typhoon Sinlaku:

Control (CTL): Radiosondes, AMVs originally processed by JMA and extracted from the NCEP/GFS dataset, aircraft data, station and ship surface pressure data, JTWC advisory TC positions.

CIMSS T: Add only CIMSS single view $(15 \mathrm{~km})$ retrieved T profiles from AIRS.

CIMSS Q: Add only CIMSS single view $(15 \mathrm{~km})$ retrieved Q profiles from AIRS.

CIMSS T+Q: Add both CIMSS retrieved T and Q profiles from AIRS.

TPW: Add only CIMSS processed AMSR TPW data.

ALL AMV: hourly and 15-min CIMSS-derived AMVs replace the JMA cloud winds, at 3-hourly intervals (00, 03, 06 UTC ...) of the control run. The cloud winds within 1-h of the analysis times ( $>=-1 \mathrm{~h}$ and $<=+1 \mathrm{~h}$ ) are used.

ALL: Add CIMSS AIRS T+Q soundings, CIMSS AMSR TPW and ASCAT data to the RSwind analyses.

All the assimilation cycles started Sep. 1, 2008. A 9km moving nest grid with feedback to a $27 \mathrm{~km}$ grid in the forecasts was used during the presence of Sinlaku. The cycling frequency was 3 hours in those cycles that used AMVs (RSwind and ALL), and 6 hours in all other cycles. An example of the distribution of the CIMSS T, CIMSS Q and TPW data, assimilated every 6 hours, is shown in Figure 7. 


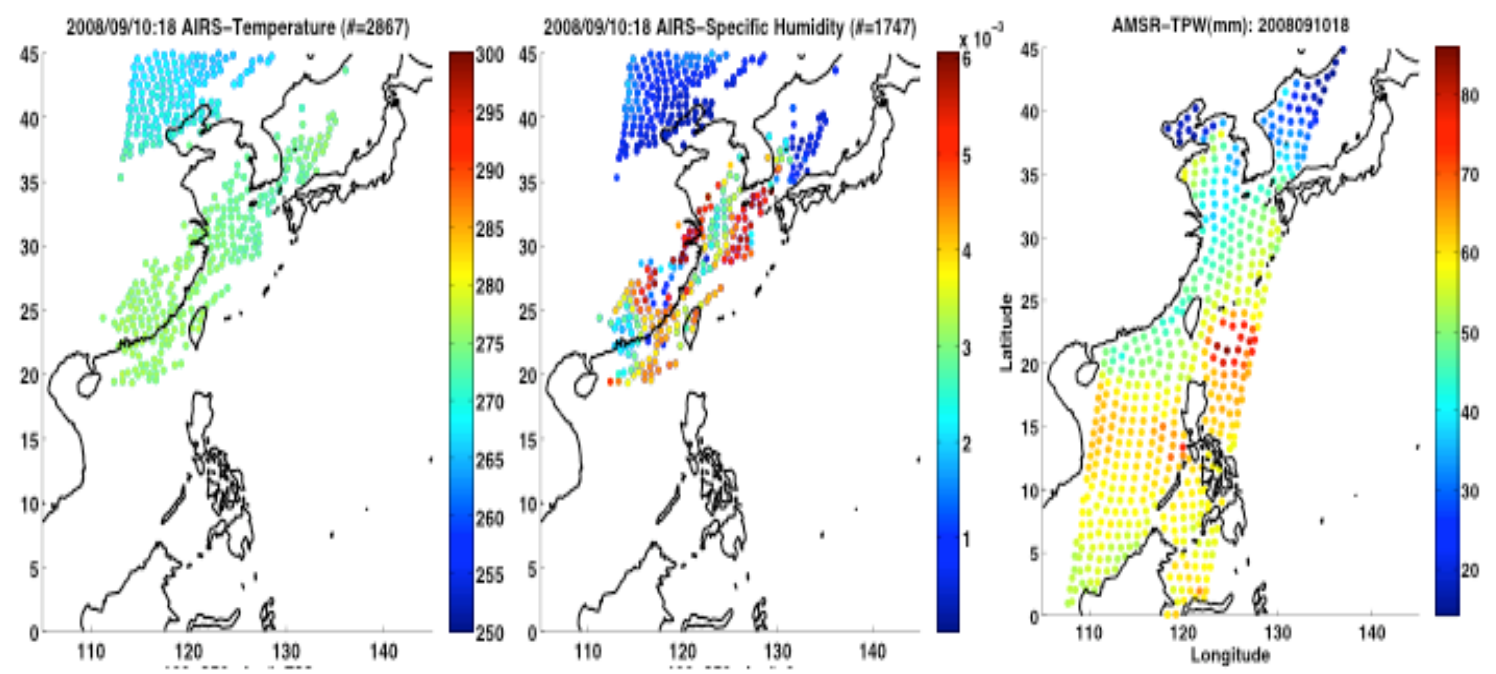

Figure 7. Left two panels: Spatial distribution of AIRS profiles of temperature and specific humidity in the CIMSS-T and CIMSS-Q assimilation cycles, for the assimilation at 1800 UTC 10 September 2008. Right panel: Distribution of AMSR total precipitable water (TPW) at the same time.

It was first found that the CIMSS T assimilation cycle served to reduce the track errors in the analysis, although the CIMSS Q assimilation cycle did not. A moderate improvement to the analysis of mean sea level pressure was found when $T+Q$ were assimilated (Fig. 8a). In contrast, the assimilation of AMSR TPW greatly improved the mean sea level pressure (and track) analyses. The assimilation of all available AMVs provided a larger improvement in the mean sea level pressure analyses of the intensifying typhoon (up to 0000 UTC September $10^{\text {th }}$ ) compared with T+Q (Figs 8a,b). Assimilating all the available satellite data ("ALL”) yielded a further improvement. The track errors were also found to be reduced due to the assimilation of the AMV data, with a little additional improvement in the early stages of Sinlaku's life cycle when thermodynamic satellite data were added ("ALL") (Figs 8c,d). In all these results, the benefit of combining the multiple dynamic and thermodynamic datasets was realized. 


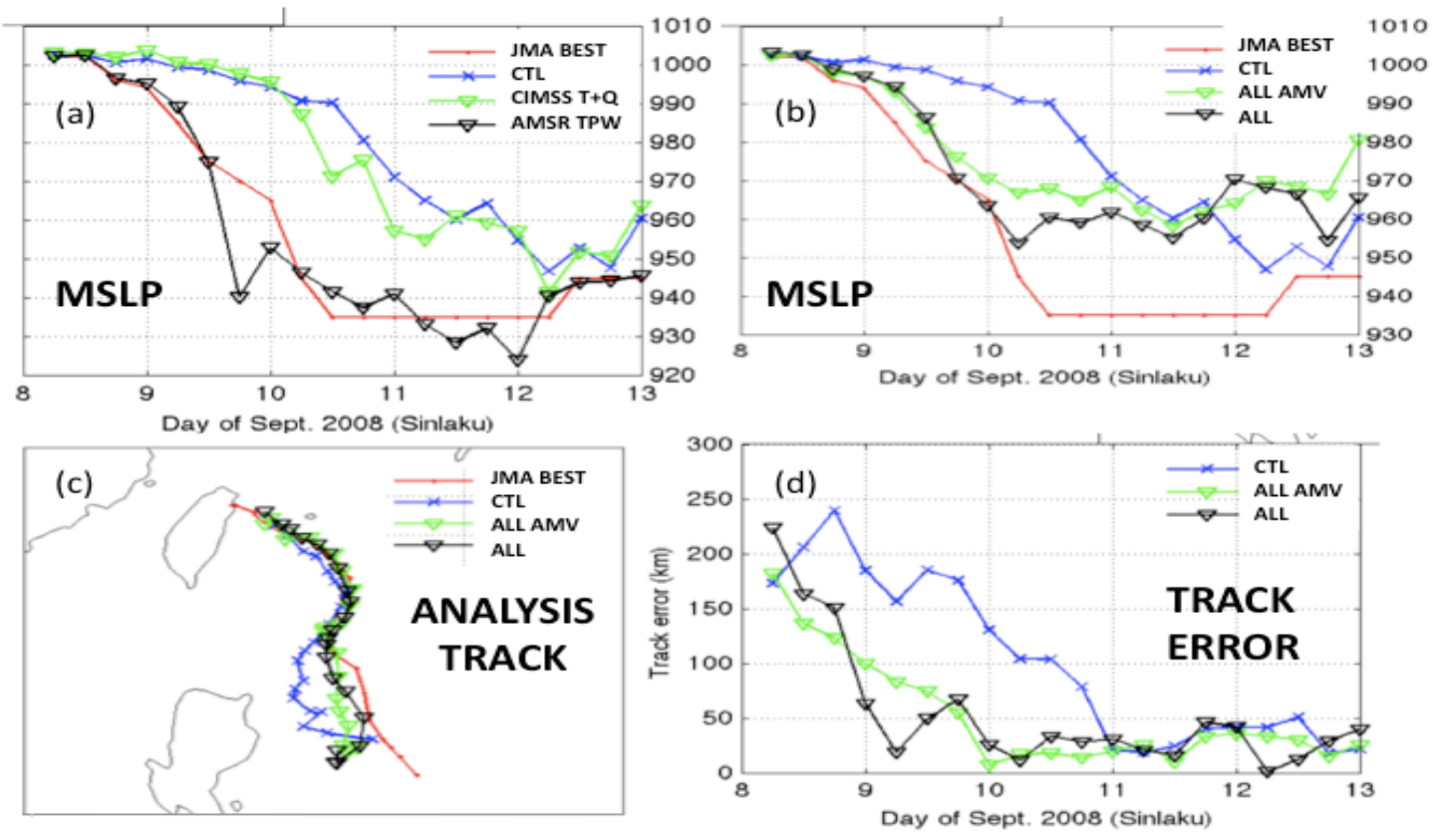

Figure 8. (a) Minimum sea level pressure in mean WRF/EnKF analyses for Typhoon Sinlaku, for the CTL, CIMSS T+Q and AMSR TPW cycles, compared against the best track. (b) as for (a), but for the cycle with ALL AMVs, and the cycle with all available satellite data assimilated. (c) Analysis track locations for the same cycles as in (b). (d) Corresponding track errors.

\section{Quality Control experiments}

Given the uncertainty in how to prescribe observational errors for hourly and 15-minute AMVs, and for TPW data, different quality control (QC) methods were pursued collaboratively by the NCAR and University of Miami teams.

For the AMVs, a new QC procedure was developed with the following criteria:

- AMVs with EE $>6.5 \mathrm{~m} / \mathrm{s}$ are ignored

- AMVs with EE $>4.5 \mathrm{~m} / \mathrm{s}$ and wind speed $<25 \mathrm{~m} / \mathrm{s}$ are ignored

- AMVs with EE $>3.0 \mathrm{~m} / \mathrm{s}$ are assigned a 50\% larger error than the NCEP GFS cloud wind error

With this new QC, the analyses of the intensity with in the assimilation cycles with the hourly and rapid-scan AMVs were further improved.

As for TPW, while the ensemble mean MSLP in Fig. 8a due to the assimilation of TPW data is substantially closer to the best track, this does not tell the entire story. The 3-day forecasts from these from these analyses are actually degraded, with a larger southward track bias (figure not shown). To explore this, experiments to test the sensitivity of TPW data assimilation to the observational error were performed. It was found that when the observational error of TPW was increased from $0.35 \mathrm{~cm}$ to $0.75 \mathrm{~cm}$, the 3-day track forecast bias was considerably reduced. 


\section{Recent improvements to WRF/DART}

The WRF/DART ensemble was found to have deficiency in its spread, particularly in the lower troposphere. In order to better represent the forecast uncertainty due to model physics, a stochastic backscatter kinetic energy forcing (SKEB, Berner et al., 2011) has been applied to the WRF ensemble when it is integrated forward 3 hours (for those cycles including AMVs) or 6 hours during the assimilation cycle. For the Typhoon Sinlaku case, it was found that the introduction of SKEB not only inflated the ensemble spread as desired, but also reduced the mean errors in the 72-hour forecasts of track and minimum sea level pressure.

Over the next year, the full suite of numerical assimilation-forecast experiments for Typhoon Sinlaku will be run by the NCAR group with this new model improvement, in order to re-evaluate the impact of the various satellite observational types.

\section{$\underline{\text { University of Miami-PI Majumdar }}$}

The WRF/EnKF ensemble analysis and forecast fields are being investigated and evaluated in depth by Ting-Chi Wu, the Ph.D. student supported by this grant. Much of the focus over the past year has been on the influence of assimilating the extra hourly and rapid-scan AMVs for the Typhoon Sinlaku case, for the new configuration of 84 ensemble members prepared at NCAR. A large number of new data assimilation and ensemble forecasting experiments, and development of new diagnostic tools has been conducted, and a manuscript will be submitted shortly to Monthly Weather Review.

The following data assimilation experiments have been completed by NCAR and U. Miami, with the aforementioned EE and Quality Index values applied:

Control (CTL): As listed above in NCAR section, 6-hourly cycle.

CIMSS (h): CIMSS processed hourly AMVs replace the AMVs in CTL, 3-hourly cycle.

CIMSS (h+RS): CIMSS processed hourly plus rapid-scan AMVs, available after 1800 UTC, 10 September 2008, 3-hourly cycle. The volume of AMVs is shown in Fig. 9.

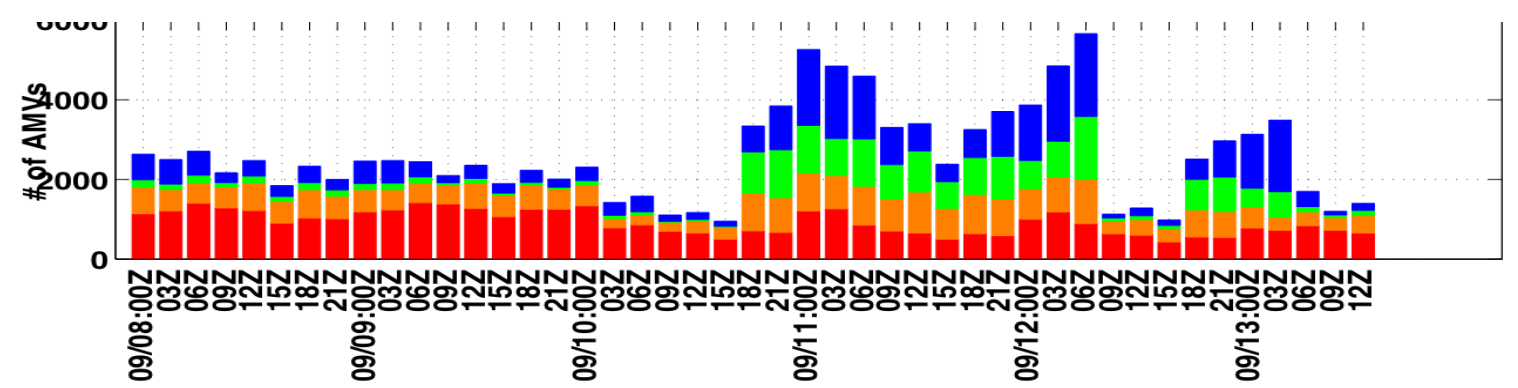

Figure 9. Number of AMVs assimilated in CIMSS(h+RS) as a function of analysis time during the period of Typhoon Sinlaku. Red: 100-250 hPa; Orange: 251-400 hPa; Green: 401-700 hPa and blue: $701 \mathrm{hPa}$ and above. 
The improvement in WRF/EnKF analyses due to assimilating the hourly AMVs in CIMSS(h) versus those AMVs assimilated at NCEP was reported in the Year 2 report. Sixteen-member ensemble forecasts were integrated from the respective ensemble analyses. The forecasts initialized from the CIMSS(h) cycles were also found to be substantially improved, particularly at the earlier times when Sinlaku was a less well organized storm with high uncertainty in its track and structure (Fig. 10a). This was due to the modification to the flow in the environment of Sinlaku arising from the assimilation of the hourly AMVs, and also the improved structure of Sinlaku (Fig. 10b). A comparison between Figs 10c and 10d indicates that a warming in the analyzed inner core of Sinlaku is present when the hourly AMVs are assimilated, producing a (correctly) more well developed typhoon during its period of rapid intensification. As was evident in Fig. 8b, the typhoon took about a day longer to develop in the CTL cycle, missing the rapid intensification period. Of particular note here is that the assimilation cycles in Figs 10c and 10d only include AMV data, and therefore indicate significant thermodynamic changes even though only dynamical fields (wind vectors) are being assimilated.
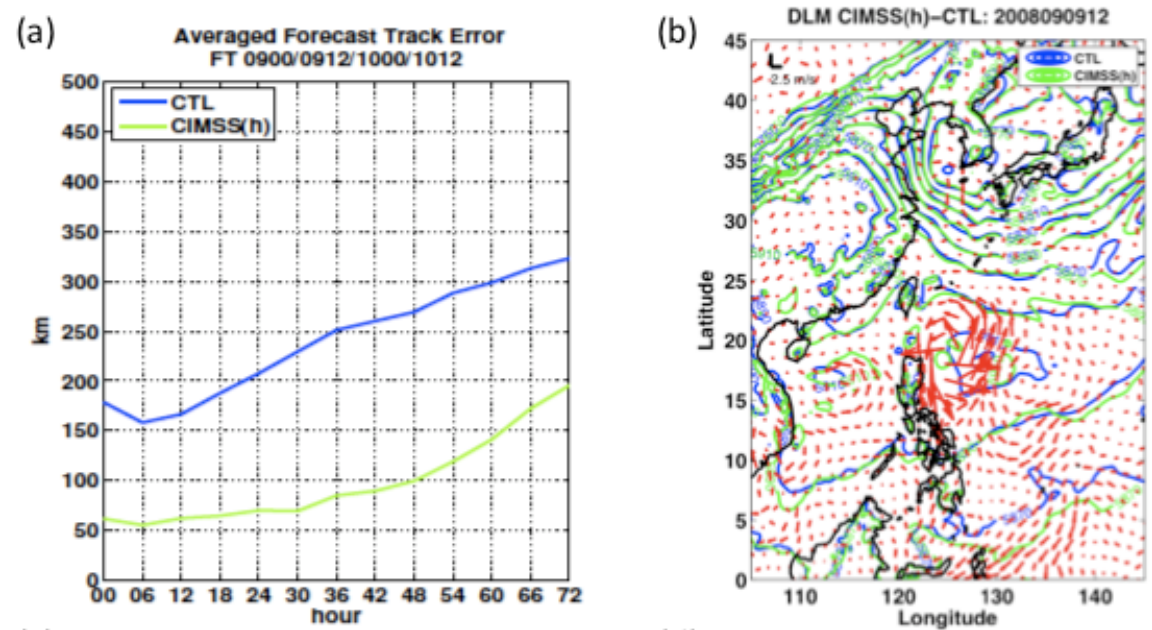

(c)

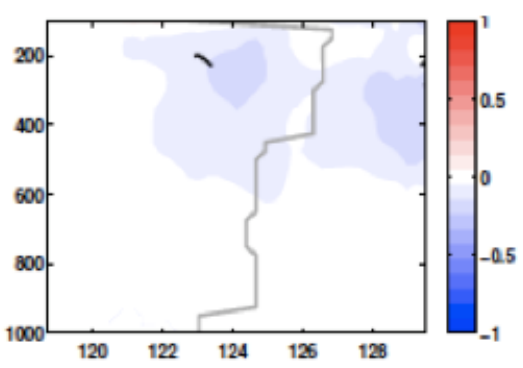

(d)

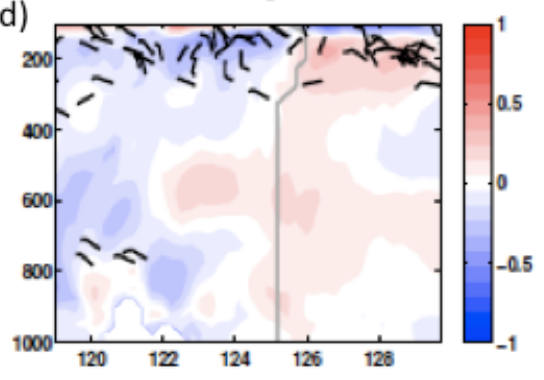

Figure 10. (a) CTL and CIMSS(h) track forecast errors for Sinlaku, averaged over all 16 ensemble members over four initial times 0000 UTC $9^{\text {th }}, 1200$ UTC $9^{\text {th }}$, 0000 UTC $10^{\text {th }}$ and 1200 UTC $10^{\text {th }}$ September 2008. (b) Red: wind vector differences between CIMSS(h) and CTL analyses at 1200 UTC $9^{\text {th }}$ September 2008. Blue: CTL $500 \mathrm{hPa}$ height analysis at the same time. Green: CIMSS(h) height analysis at same time. (c) Change in CTL temperature analysis in vertical cross-section of Sinlaku during its period of rapid intensification. (d) As in (c), but for CIMSS(h) cycle. 
Attention has also been focused on the influence of assimilating the rapid-scan AMVs on ensemble analyses and forecasts. Generally, since Sinlaku was a well-developed typhoon by the time rapid-scan mode was activated, and furthermore the CIMSS(h) data had already contributed to a vastly improved representation of a rapidly deepening typhoon, the additional contributions of the rapid-scan data for this typhoon were more subtle. A larger number of ensemble members in the CIMSS(h+RS) forecasts recurved Sinlaku near Taiwan, thereby preventing an erroneous forecast of landfall over China (Fig. 11a). Some ensemble members initialized at later times even predicted recurvature too strongly. The rapid-scan AMVs far to the northeast of Sinlaku acted to lower the geopotential height field in a mid-latitude trough, thereby weakening the subtropical ridge over the western Pacific Ocean, and allowing for an earlier recurvature of Sinlaku (Fig. 11b). In addition to the track, ongoing investigations suggest that the vertical structure of Sinlaku in the CIMSS(h+RS) analyses was more consistent with nearby aircraft dropwindsonde data (not assimilated) than the CIMSS(h) analysis.

(a)

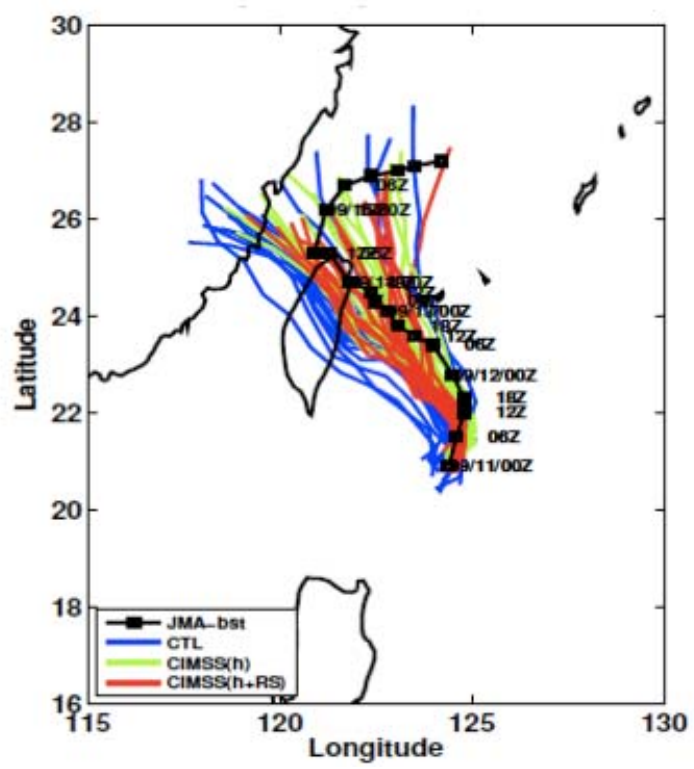

(b)

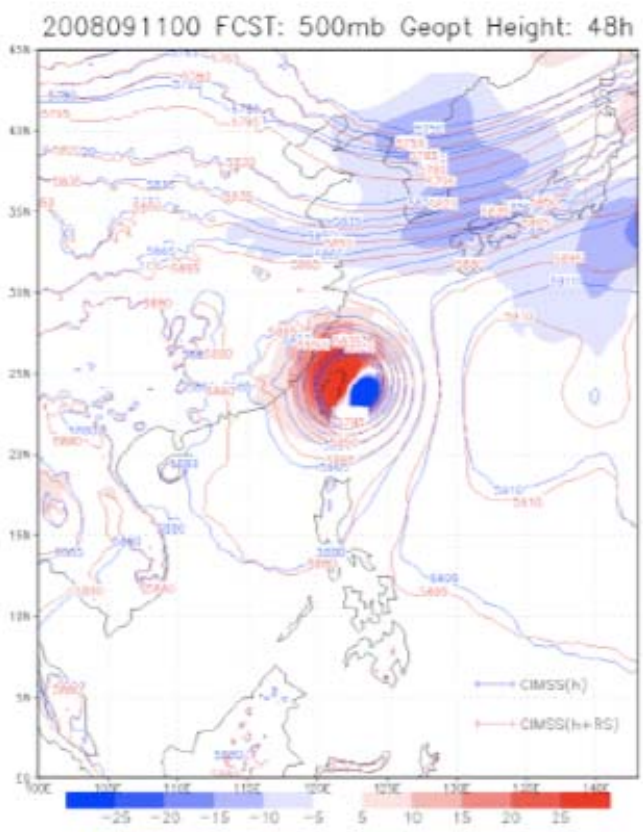

Figure 11. (a) 3-day, 16-member WRF ensemble forecasts of the track of Typhoon Sinlaku, for the CTL (blue), CIMSS(h) (green) and CIMSS(h+RS) (red), initialized at 0000 UTC $11^{\text {th }}$ September 2008. (b) Shading: difference between CIMSS(h+RS) and CIMSS(h) 2-day forecast of $500 \mathrm{hPa}$ geopotential height. The $500 \mathrm{hPa}$ geopotential height contours of the two respective forecasts are shown for reference.

Over the next year, the scientific foci will be in two areas. The first will be a detailed diagnostic investigation of the influence of assimilating AIRS T and Q profiles, TPW data and combinations of these datasets and the AMVs. The second study will identify the importance of assimilating high-resolution AMV data (from the rapid-scan mode) in 
certain regions, organized by level and/or location (Fig. 12). Results will be documented in the Final Report in 2013, and submitted to the peer-reviewed literature.

Finally, discussions are continuing with data assimilation researchers at NOAA about the potential to include the various types of satellite data in NOAA's data assimilation schemes for hurricane models.

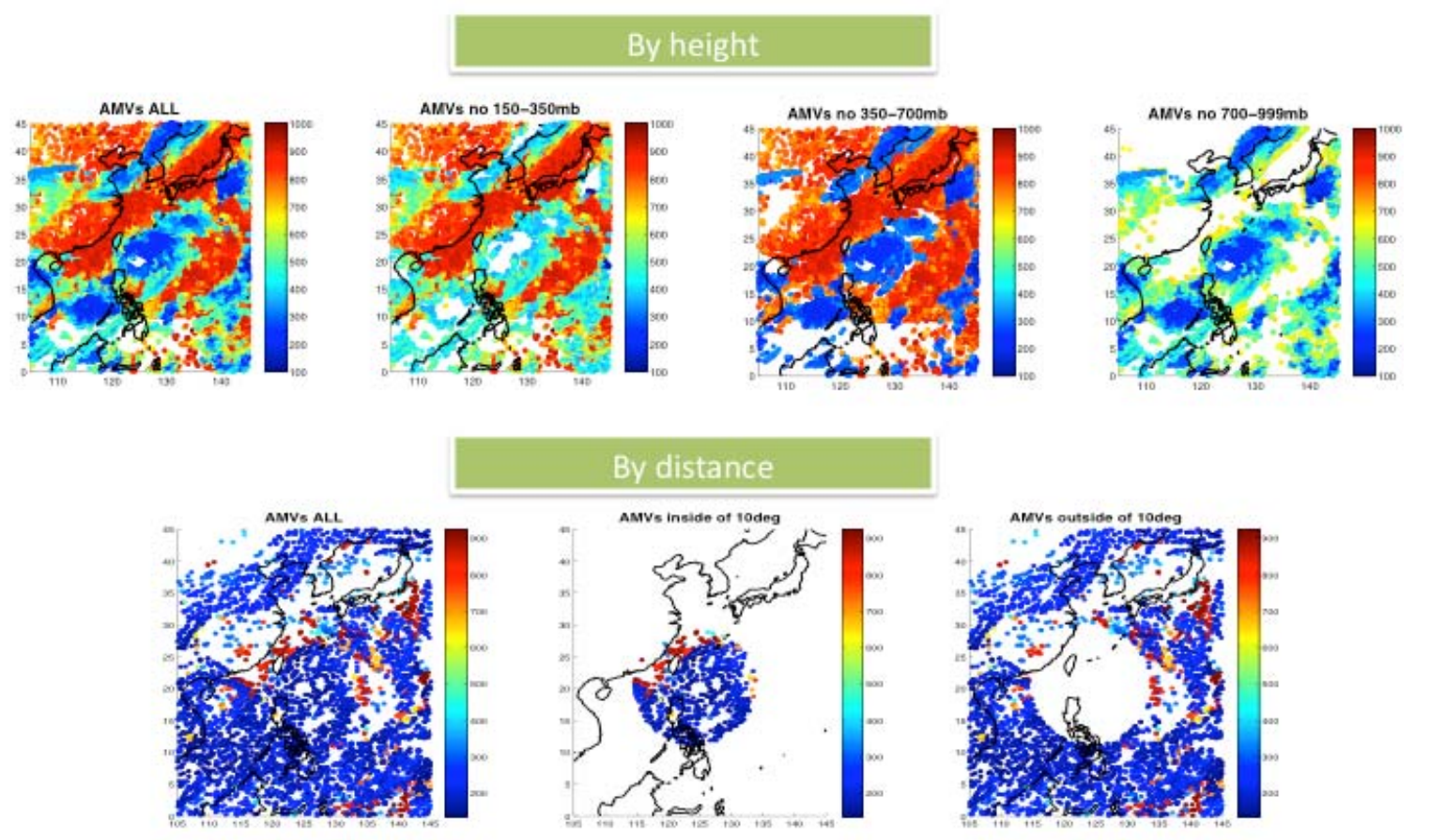

Figure 12. Sample distributions of AMVs for forthcoming data-denial assimilation experiments using rapid-scan AMVs. Top: AMVs in certain layers removed. Bottom: AMVs removed inside and outside a circle centered on the typhoon.

\section{IMPACT AND APPLICATIONS}

\section{National Security}

Improved forecasts of tropical cyclone intensity, through the optimal assimilation of high-resolution satellite data, are expected to lead to more advanced and accurate warnings for Naval vessels and therefore relocation when necessary.

\section{Economic Development}

Improved predictions of tropical cyclone intensity are expected to allow valuable additional time to prepare properties and businesses in case of a potential impact, thereby mitigating damage costs that may be crippling. 
Quality of Life

Improved predictions of tropical cyclone structure will lead to better preparation for and responses to potential storm surges, and an improved ability to manage coastal resources after the impact.

Science Education and Communication

This NOPP project has contributed to educating undergraduate and graduate students on several types of satellite data that are important for tropical cyclone analysis and prediction. Furthermore, students have been trained on advanced data assimilation, and high-resolution modeling of hurricanes. The PIs and their staff and students have communicated these scientific issues and tools to a variety of audiences, in professional meetings and in public lectures. Some of the material and software from the project will continue to be used in future university courses and to train new students on modeling and data assimilation.

\section{TRANSITIONS}

Science Education and Communication

Via this NOPP project, the continued advancement of data assimilation and hurricane modeling in NCAR's WRF-DART system and the Navy's COAMPS-TC has taken place, with new versions accordingly being made available within the Navy and to the external community. The future use of these improved prediction systems will feed back as described in the "Impact and Applications" section.

\section{RELATED PROJECTS}

This project is related to that funded to CIMSS by ONR grant N00014-08-1-0251: "Advanced Satellite-Derived Wind Observations, Assimilation, and Targeting Strategies During TCS-08 for Developing Improved Operational Analysis and Prediction of Western North Pacific Tropical Cyclones” (PIs Velden and Majumdar).

Another project at CIMSS that is related is "High impact weather studies with advanced IR soundings", funded by the NOAA GOES-R program office (PI Li).

Work at UCAR is related to a NASA GNSS proposal: “Improving Tropical Prediction and Analysis using COSMIC Radio Occultation Observations and an Ensemble Data Assimilation System with Regional and Global Models (PI Anderson). Also, a NCAR-CWB (Taiwan Central Weather Bearou) cooperative project "The Enhancement of the CWB Data Assimilation System (PI: Bill Kuo). Finally, a related NASA proposal submitted and in review "Evaluation of Hyper-spectral 
IR Data in Storm Forecast with Regional WRF/DART Ensemble Data Assimilation System" (PIs Liu and Li).

This project is also related to that funded to the University of Miami by ONR Grant N00014-08-1-0250: "Using NOGAPS Singular Vectors to diagnose large scale influences on tropical cyclogenesis”. The MATLAB code for dynamic initialization of tropical cyclones developed on that grant has been shared and is being used by CIMSS in their data assimilation studies which use an ensemble of 'bogus' tropical cyclone vortices in their first guess field.

Work at NRL Monterey is related to three projects: (i) ONR PMW-120: "Prediction of Tropical Cyclone Track and Intensity Using COAMPS-TC"; (ii) the COAMPS-TC component of the NOAA Hurricane Forecast Improvement Project, and (iii) a NOPP (NOAA/ONR) award on Air-Sea Interaction.

\section{PUBLICATIONS}

Kwon, Eun-Han; Jun Li, Jinlong Li; B. J. Sohn, and E. Weisz, 2012: Use of total precipitable water classification of a priori error and quality control in atmospheric temperature and water vapor sounding retrieval. Advances in Atmospheric Sciences, 29, $263-273$.

Wu, T.-C., H. Liu, C. Velden, S. Majumdar, and J. Anderson, 2012: Influence of assimilating satellite-derived atmospheric motion vector observations on analyses and forecasts of tropical cyclone track and structure. To be submitted to Mon. Wea. Rev.

Zheng, J., J. Li, Jinlong Li, and T. J. Schmit, 2012: Assimilating AIRS Soundings with WRF/3DVAR for Hurricane Forecast Improvement, Journal of Applied Meteorology and Cimate (to be submitted).

\section{HONORS/AWARDS/PRIZES}

Co-PI Majumdar was appointed a Co-Chair of the American Meteorological Society's annual conference on Integrated Observing and Assimilation Systems for the Atmosphere, Oceans and Land Surface (IOAS-AOLS), held at the AMS Annual Meeting.

Co-PI Velden was awarded the University of Wisconsin Chancellor's Award for Distinguished Research 